\title{
Understanding the Effects of Temporal Differences in User-Centered Workflows on Solution Satisfaction
}

\author{
Daniel N. Treku \\ The University of Texas Rio Grande Valley \\ daniel.treku01@utrgv.edu
}

\author{
Jun Sun \\ The University of Texas Rio Grande Valley \\ jun.sun@utrgv.edu
}

\begin{abstract}
Technology-induced changes to workflows may not necessarily lead to user satisfaction with solutions expected at the end of each workflow. This eventually affects project success. The study investigates user expectation and confirmation regarding cognitive agreement with the changes from old paper workflows to new electronic workflows. In particular, a research model is developed with two mediated routes between user expectation and solution satisfaction: one route is via perceived workflow agreements and the other via perceived performances. Based on longitudinal survey data of 118 participants in an institution that recently underwent a major transition in workflows, it was found that old workflow agreement influenced solution expectation more than old perceived performance, but new perceived performance impacted solution satisfaction more than new workflow agreement.
\end{abstract}

\section{Introduction}

The advances in information and communication technologies continue to change the fabric of organizations in more rapid and complex ways than before [33]. Workflow changes resulting from these rapid technological advancements induce shifting user cognitions and behaviors. Such shiftings create new workflow expectations that largely shape employees' satisfaction with the technology solutions. This phenomenon highlights the need for both cognition and emotion in theorizing user behavior for a better understanding [4]. This study examines the affective process of solution expectation, confirmation and satisfaction based on user cognitions of workflow agreement and performance before and after workflow changes.

The relevance of workflow consideration cannot be overstated. Consider the outcome for an organization if all employees have a $10 \%$ effective increment in the rate of solving customer service problems or complete tasks $10 \%$ faster than before or getting products $10 \%$ faster to the market due to some modifications or changes in their organization's technology system. An estimation by Integrify - a workflow automation software company - suggested that a company of 250 employees that sees a $10 \%$ gain in productivity will see an average gain of $\$ 1.125$ million per year [23]. Aggregately, and for several organizations, such macro-level estimation (unit or organizational level) may be reflective of the impact of individual or usercentered improvements in system use and tasks completion [24].

At the user level and in a mandatory technology use context, several perspectives such as the influence of network structure and social capital in information system appropriation have been used to estimate users' tasks execution and their impacts on the success of an information system, and to a larger extent, the productivity of an organization [24, 29]. These studies also advance the importance of advice networks and knowledge sharing to improve system usage. Extant studies have also advocated the relevance of selfefficacy and user trainings [25, 26] at the user-level. However, little is known from the extant literature about user-centered cognitive estimations regarding the continual and effective use of the technology following changes to the user's workflows in a mandatory setting. We argue that amid advice solicitations among users in organizational social networks [29], users will cognitively assess and estimate the information exchanged in their network. Also, various literature streams, especially in Information Security (IS), have shown that there are unexplained mechanisms between users' expected compliance to system use requirements and their experiential use which go beyond training (e.g., Barlow et al. [3]). These mechanisms continue to call for deeper and context-specific explanation of user behaviors to optimize system usage and improve productivity in the organization [10].

As such, regarding workflow changes, this study argues that more focus on the evaluation of usercentered workflows and associated cognitions could be pivotal in generating better understanding of an individual's usage slowdowns that might hamper 
organizational productivity. Notably, theorizing effective user-centered workflow-related continuous use provides an opportunity for a richer IT usage conceptualization by capturing user, task, and system with appropriate constructs [9]. As this study investigates the transition from paper workflows to electronic workflows, the concept of system covers both IT-based and traditional means for users to complete certain type of tasks. Sykes and Venkatesh [29] refer to this richness as deep structure (also, see Zhang [34]) in their study of social ties in enterprise systems use and how these ties affect job performance in an organization. By considering workflow as a richuse or deep-structure concept, a connection between workflow changes and performance impacts can be made [30].

The literature on IS continuance employs variables, like perceived usability, usefulness and enjoyment to capture user system-related experiences [14, 30]. Different types of systems, thus, provide different user experiences [16]. In this study, workflow agreement is proposed as a system experience construct to understand how the technology-induced workflow change impacts user affective processes in addition to task performance, which is assumed as essential for optimizing the usage extent and productivity [30]. Furthermore, the study examines how system experience and task performance before and after workflow transition influence users' emotional development in terms of expectation and confirmation $[5,16,21]$. The eventual outcome variable is user satisfaction that has been recognized as the strongest predictor of continuous product engagement $[5,15]$.

The paper proceeds as follows. First, it reviews the literature on research background and relevant theories. Then, it develops a research model that hypothesizes the relationships among research variables. The methodology section describes how a survey was conducted to test the research model. Observations are analyzed, and results are interpreted, followed by the discussion of the implications for theory and practice.

\section{Literature Review 2.1. Workflow Changes}

Workflows have been argued in some studies as business process elements vital for job performance (e.g., Sykes and others [30]). Workflows are not isolated parts of the physical technology system but intertwined with the use of the technology system [30]. We define workflows as the set of tasks-grouped chronologically into processes - and the set of people or resources needed for those tasks, that are necessary to accomplish a given goal. However, studies from industry and to some extent academia have advanced the establishment of workflow management scheme about the IT use to enable the organization to meet the constituent demands and aid effective allocation of resources across the work channels. These studies focus on work units and aggregate interactions among users in the unit. Unit-based or aggregate-based consideration accounts for about " $30 \%$ of all major change activities in organizations today" [20] (p.143). This aggregate-based view of workflow only serves as a black-box in organizational workflow phenomenon [22]. The sum of individually-related phenomenon may not be enough to elucidate nodal disparities in a system. This consideration calls for further explicit theorizing to understand disparities relating to usercentered workflows. Thus, understanding user-centered engagement with workflow changes could contribute more in explicating this $30 \%$ change impact due to technology changes [20]. Again a deeper level understanding of workflow changes in the organization is key in designing characteristics of tasks that fit technology features and optimizes specific-user appropriation of the technology system [14].

Sykes and Venkatesh [29] explored the relative performances identified with workers based on the different pieces of advice they receive from company's social network (i.e., from other colleagues) on their specific and mandatory user-centered workflows when appropriating enterprise systems. Their study provides a vital contribution on how different social relationships (i.e., friends or acquaintance) affect job performance. They add that, underlyingly, an advice given requires cognitive approval or agreement made on whether to utilize it or not. This study argues that workflow advice is likely to be scrutinized by the user based on their present use and prior experiences of the technology. As this advice engages the user's prior experience or cognitive decisions about their old workflows, it is the outcome of this cognitive engagement that would determine the premium placed on that advice; whether to revere it, confirm it or disconfirm it. Their study, therefore, advances our knowledge of faithful appropriation in a socioorganizational context. This study asserts that the body of knowledge in the literature can be extended if we understand how these cognitively assessed faithful appropriations come to be realized (or instituted), even after advice is given, and how these cognitions affect one's satisfaction (i.e., positive emotion) regarding expected solution. This line of reasoning is supported by literature on cognitive absorption which inextricably links the notions of individual's personality trait dimension of absorption, the state of flow and cognitive engagement [1]. This literature emphasizes cognitive load processing when cues and messages engages users' mind (e.g., Zhang [34]). Our 
reasoning is also supported by the cognitive dissonance literature and the social-cognitive literature streams (e.g., Bhattacherjee and Premkumar [8], and Festinger and Carlsmith [13]). At the core, these streams of research, generally, project how beliefs are enforced and how users make choices (rationalize) when confronted with having to decide between their attitudes and beliefs. One notable study that underscores our notion of cognitive agreement about technology-induced changes is Kjaergaard and Jenson's [19] case study on cognitive mapping. They argue the value of cognitive mapping "as a facilitating technique of individual reflection, as well as [his/her] collective negotiation and construction in relation to technology adaptation" (p. 1097). Their study represented user interpretations (from data) as cognitive maps that could be leveraged for further work assignment and accomplishment. This study identifies this conception of mental representation as workflow agreement. Workflow agreement represents individuals' decision outcomes after processing pieces of advice from other colleagues, and signals from the work environment. To this, the present study sets out to explore how old workflow agreement and new workflow agreement impact further user engagement following changes to the task-technology system of the organization. Formally, workflow agreement is defined as the cognitive buy-in that users have about the procedure to follow as imposed by an information systems or traditional means (e.g., paper documents). Succinctly, this study advances that there is the need to assess individual's cognitive lock-in in the technology being negotiated more explicitly by studying temporal differences in the agreement about specific workflows.

\subsection{Expectation-Confirmation Theory}

Expectation Confirmation Theory (ECT) [21] also known as expectation-disconfirmation theory (EDT) is a primary theory in the marketing literature particularly in the consumer behavior literature [12]. ECT argues that consumers' overall satisfaction or dissatisfaction about a product informs their re-purchase intention. A priori, the theory suggests that people form expectations about the use of a product based on their perceptions, perspectives, experiences which are either confirmed or disconfirmed [31]. Consequently, this drives their satisfaction and intention about the product. The intention formed could lead to either a purchasing behavior or non-purchasing behavior or complaint or different combinations of these [15]. Because of the theory's relation to general product use and elegant explanation, ECT has been applied in many contexts and disciplines. In what has become widely known as the IS continuance model [4], ECT was adapted to explain users' propensity to continue using a technology. Specifically, the mediating principle of IS continuance is premised on not just an extension of IT acceptance but the inclusion of psychological and affective motivations that emerge after initial usage stage $[6,8]$. These motivations subsequently condition acceptance-resistance dialectics to explain continuous use intention and IS continuance.

In a study, Bhattacherjee and Premkumar [7] integrated EDT and IT use literature to advance the Bhattacherjee-Premkumar (hereafter BP) model (also known as the two-stage temporal model of cognitive change). The BP model posits that disconfirmation and satisfaction are key drivers to cognitive changes about a user's perceived usefulness of the IT. Xu and others [32] adapted the BP model in their study hedonic IT use (i.e., use of iPad) for problem-solving at different times. They explain that perceived enjoyment of IT is salient at the onset of adoption but whereas perceived usefulness is not significant. However, perceived usefulness becomes salient with continuous usage of the technology. In effect, different contexts provide researchers opportunities to measure users' several unique expectations about a phenomenon. Recently, Islam and colleagues [16] proposed a decomposed expectation-confirmation model of IT continuance and posited role of perceived usability at different measurement times (i.e., $\mathrm{t} 1$ and $\mathrm{t} 2$ ). The study focused on a unique expectation variable - perceived usability. Based on a longitudinal data set from 125 LinkedIn subscribers and empirical analysis, the study posits that perceived usability plays a more critical role in forming expectations than perceived usefulness. They also note that satisfaction fully mediates the effects of usefulness on intention to continue.

In the traditional marketing sense, consumers reach re-purchase intention decisions based on expectations learned from knowledge of the product and interactions with other members of the community [7]. Expectations are beliefs or experiences that users form regarding their decisions on products or artifacts. In the present study, it assumed that increased satisfaction due workflows may have connotations with performance measures. Several studies have also looked at how expectations about performance impact one's satisfaction [18]. This study explores how prior expectations and new expectations regarding changes to workflows inform users' satisfaction.

Furthermore, the study attempts, as shown in the research model, to compare how these workflows relate to the well-established expectancy-performance models for predicting user satisfaction. This focus is due to two reasons: First, in a mandatory setting, the user has a responsibility to use the technology to perform mandatory tasks so measuring his/her 
satisfaction which informs the optimal usage at time $t$ is of the essence. Secondly, there is enough support in the literature on ECT that when users are very satisfied with a product, there is a high chance they will continue to utilize that product.

In sum, this study notes that the ECT/ IS continuance literature is extant, and there are several contributions to date. However present arguments in ECT literature regarding theorizing context-specific affective processes (e.g., Islam et al. [16]) afford this study an opportunity to theorize solution expectation about workflow changes, workflow agreements and their and effects on solution satisfaction. For brevity and space in this conference manuscript, key studies have been highlighted. For a systematic review of this literature, see studies by Bhattacherjee and Lin [6], and Hossain and Quaddus [15].

\section{Research Model}

In an organization that undergoes a major workflow transition, people's work agreement and task performance are likely to shift. From an expectationconfirmation perspective, the study theorizes their two routes of influences and compares their effects as specified in a research model (Figure 1). This study posits that workflow agreement and task performance before and after the transition shape user emotional development. User expectation and confirmation eventually lead to solution satisfaction that result in continuous use [18]. In the context of workflow improvement and mandatory settings, therefore, user satisfaction with a new solution is a more meaningful predictor than the behavioral intention on whether to adopt a new system or not.

In most expectation-confirmation literature, expectations are conceived to precede perceived performance [18], or they are thought to have satisfaction directly with no linkages to perceive performance (e.g. [5] and [16]).

However, for a technology system in a mandatory setting with almost $100 \%$ technology-savvy user rate; it is conceivable that their prior flexibilities in faithfully appropriating a technology and their desires of how the technology should relate to their workflows would inform their new expectations about a new technology event. In sum, perceptions about the old performance of the technology and related cognitive appraisal of the ease and effectiveness of the associated workflow will form users' expectations in appropriating new technologies and consequently their positive or negative appraisal of overall solution as satisfactory or not. We, therefore, posit the following:

Hypothesis 1(H1): Old workflow agreement will be positively related to solution expectation
Hypothesis 2(H2): Old perceived performance will be positively related to solution expectation.

Task-technology fit theory [14], suggest the need for task requirements or workflow to relate to a specific feature of a technology in increasing productivity and overall system satisfaction [5]. This has been argued to offer a theoretical link to use, as such, it has widened the domain conceptualization of use [2]. Workflows have tight coupling with deep structure use (tight coupling of a business process with software) and would influence job performance positively [30]. Thus, in context of the current study, the overall satisfaction of solution is provoked by the technology (features or software, the tasks, and the users' faithful appropriation and quality of interaction, i.e., technology advice network) that binds the various units together. Therefore, workflow agreement denotes the degree of task-technology fit regarding users in a group. It captures their perceptions of how the technology should function in performing their technology-related tasks (Sambamurthy, 1989). This is also the "extent to which the technology is used in a manner consistent with the general objectives and procedures that it aims to promote and use" [11]. Users' past or old fit evaluations, cognitive and consequent emotional appraisals regarding their own and the technology's performance at the initial or prior stages have been argued to form long-lasting emotional impact on users [4]. It is only the process of adaptation regarding their workflows and how new perceptions provoked by new IT events may change their 'affective' status. Therefore, it is imperative to understand old performance perceptions that have inspired expectations as well as the impact of old workflows or task-technology fits. Hence, we state the following:

Hypothesis $3 \boldsymbol{a}(\mathrm{H3a})$ Old workflow agreement affects new workflow agreement

Hypothesis $3 \boldsymbol{b}(\boldsymbol{H} 3 \boldsymbol{b})$ : Old perceived performance affects new perceived performance.

Users' old expectations or beliefs play a role in new expectations about changes in the usage of a technology [29]. If expectations of individuals, generally and aggregately, high for the group; and these expectations are not met although the technology might have generally met broad task-technology fit expectations of the different individuals that make up the institution, high cognitive appraisal will ensue in ascertaining whether the performance of the technology is worth the required tasks or workflows. If the appraisal is negative just after initial experience with the new technology, perceptions and issues with tasks ease of use will be negatively impacted. This is 
comparable to shake-down phase or preimplementation phase of a new technology which may affect later appropriation of the technology [27]. Previous studies have established the direct effect of expectations on performance. For established findings and expectancy-performance models (see Johnson and others [16]). Taken together, we posit the following hypotheses:

Hypothesis 4(H4): Solution expectation positively affects new workflow agreement

Hypothesis 5(H5): Solution expectation positively affects new perceived performance

ECT posits that initial expectations formed will be positively related to confirmation of these expectations if users deem that their expectations are being met in the experience of the new product or artifact $[14,20]$. However, concerning most expectancy models proffered, there are arguments of inconsistencies in findings of prior studies on expectations and confirmation. While some have reported significant relationships in their expectancy models, others have reported insignificant relationships [16]. Johnson and colleagues [16] argue that this inconsistency has to do with the kind of product or service in question and the context of the application. We posit that in a mandatory setting where new workflows are aimed at organizational improvement, there would be confirmation of formed expectations amongst users. Thus, we state the following hypothesis:

Hypothesis 6(H6): Solution expectations about new workflows positively affects solution confirmation

By extension, users' history of their task coordination regarding similar expected technology solution will inform their confirmation or disconfirmation appraisals of new workflows. "Disconfirmation is the degree to which performance exceeds, meets, or falls short of one's expectations, resulting in positive, zero, and negative disconfirmation, respectively" [22]. Users will strongly confirm solution expectations if their new expectations are higher than prior expectations in using the system. Comparatively, if their perceptions of tasks performed by the new system are higher than prior perceived performances, they are likely to confirm new solutions strongly. Thus, a confirmation suggests less expectation-experience discrepancy with respect prespecified attribute of the product or service or technology [4, 5]. We, therefore, posit following hypotheses:

Hypothesis 7(H7): New workflow agreement positively affects solution confirmation when high expectations met.
Hypothesis 8(H8): New perceived performance positively affects solution confirmation when high expectations are met.

Satisfaction has been suggested as the most significant positive valence that mainly influences continuity of any IS usage $[4,13]$. This is supported by extant research marketing literature which unquestionably theorized satisfaction as the most significant predictor of users repurchase intention [22] underscoring the relevance of satisfaction variable in theorizing continuous phenomenon. Satisfaction, in the context of job performance, was defined as "a pleasurable or positive emotional state resulting from the appraisal of one's job "[18] and later, in consumer research, as "the summary psychological state resulting when the emotion surrounding disconfirmed expectations is coupled with the consumer's prior feelings about the consumption experience" (Oliver, 1981 p. 29). In our context, product consumptions come in the mode of the context of experiencing workflows mandated by the performance of tasks on the new technology. Users new experiences about their workflows and their perceived performances will inspire a higher level of satisfaction when new solutions from the technology are better compared to their previous solutions from old experiences. We, therefore, posit the following:

Hypothesis 9(H9): Solution confirmation regarding new technology feature changes positively affects solution satisfaction.

Hypothesis 10a(H10a): New workflow agreement positively affects solution satisfaction.

Hypothesis $10 b(\mathrm{H} 10 \mathrm{~b})$ Perceived new performance positively affects solution satisfaction.

\section{Research Method}

To test our proposed model, we conducted a two time-period survey to collect data at different times. (specifically, November 2017 and March 2018). On all occasions, we collected data from students in a large university who appropriated the institution's work management system, albeit at different times. Based on IRB approval, students' emails were used to extend an invitation for participation in the study. All data confidentiality provisions and guidelines on subjects' deidentification were adhered to. The survey measurement items for all our constructs in our research model were adapted from prior literature. Measurement items for workflow agreements and performance perceptions were adapted from Goodhue and Thompson [14]. Items on solution expectation, confirmation, and satisfaction were adapted from contemporary and related studies on expectation- 
confirmation: Bhattacherjee [5, 8] and $\mathrm{Xu}$ et al. [32]. The respondents for the survey constituted students in a University in Texas, USA. The respondents answered questions on their prior usage of previous system feature (predominantly paper workflow) (t1) and their usage of the present technology feature after changes were made (t2). In this study, these systems are referred to as Campus Solutions A for old system and Campus Solutions B for new system. The technology feature changes are noteworthy because they afford different interfaces that alter users' prior cognitions and workflows. More importantly, the use of the technology is for mandatory tasks completion. Tasks are synchronized with workflows of other relevant units and across different levels of the institution for mandatory tasks assignment and execution. The current system is used together with some separate email functions and some paper-based tasks requirements. Initially, interviews were done to identify specific old workflows that were vital to students' use of the technology systems. Respondents were then assessed based on their old system usage and the new system usage; time $\mathrm{t} 1$ (campus solutions A) and $\mathrm{t} 2$ (campus solution B) respectively. Researchers provided narratives of old workflows and new workflows and asked students (using binary response) to determine whether they agreed or disagreed with each work workflow narrated. This process was done to ascertain whether the workflow narratives agreed with students' actual experiences of old and new campus solutions. For each data collection period, those in agreement were between $94 \%$ to $98.57 \%$. Final sample for analysis only included respondents that identified with the workflow. Only one workflow type was used. However, the narrations were two-fold. One narration was concerned with the old flow of work which is predominantly paper-based (Campus Solutions A), and the other depicts electronic flow of the same work (Campus Solutions B).

For the first survey protocol (in Campus Solutions A), students responded to surveys regarding old workflow and old perceived performance as well as their solution expectations as proposed in our research model. To inform respondents' solution expectations, students were shown prototypes of the expected new technology interface changes which afford a full electronic flow of the same work during the survey. This was done to graphically depict how workflows would be altered in the new system. Additionally, and although not hypothesized, data was collected on the old solution satisfaction for old system use. The significance of this measure, from our post hoc analysis, is discussed in later. For the second survey protocol (time t2), students responded to questions on Campus Solutions B, regarding new workflow, new perceived performance, solution confirmation, and solution satisfaction. The final sample used for the analyses was 118 respondents (same set of students were involved at each point of data collection) out of 163 invitations. $53 \%$ of the participants were males and $47 \%$ females. The respondents were in the age bracket of 18 and 45 years. The mean age of the respondents was, approximately, 23 years.

\section{Results}

Smart PLS 3.0 [28], a structural modeling technique, was used for data analysis and for testing the overall model. Paths significance in the structural model were ascertained using bootstrap resampling method (500 subsamples, alpha level 0.05) on the PLS. The model was tested for internal consistency reliability, composite reliability, convergent validity, and discriminant validity (see table 1 ) to determine the overall validity of the constructs in the model. We included a test for interaction effects especially new workflow agreement and new perceived performance. Except for our comparative variable - perceived performance -, all constructs were validly assessed. The $R^{2}$ adjusted values of the two primary outcome variables, solution confirmation, and new solution satisfaction were above 0.44 (45\% of the variance was explained in solution satisfaction).

We conducted post hoc analysis with different path model specifications to make certain our claims on the significant paths. The results showed no significance on the dependent variable, solution satisfaction. Intuitively we noted that expectations are high when users expect much from the technology feature changes. Thus, preceding these expectations is a level of satisfaction that may be compared with later satisfaction gained when new artifacts are experienced. We, therefore, measured satisfaction at time $t 1$, based on old experiences. We conducted a paired sample ttest to ascertain the variability in the means of old solution satisfaction (t1) and new solution satisfaction (t2) measures. The result was significant (mean difference of $1 \%, \mathrm{p}<0.05, \mathrm{t}$ value $=-2.522$ ) indicating that there are temporal differences in satisfaction levels of the user whenever there are IT-induced changes in their workflows. Our post hoc analysis showed fit indices reported for the model without perceived performance measures $(\mathrm{SRMR}=0.078$, Chi-square $=$ 372.407) 


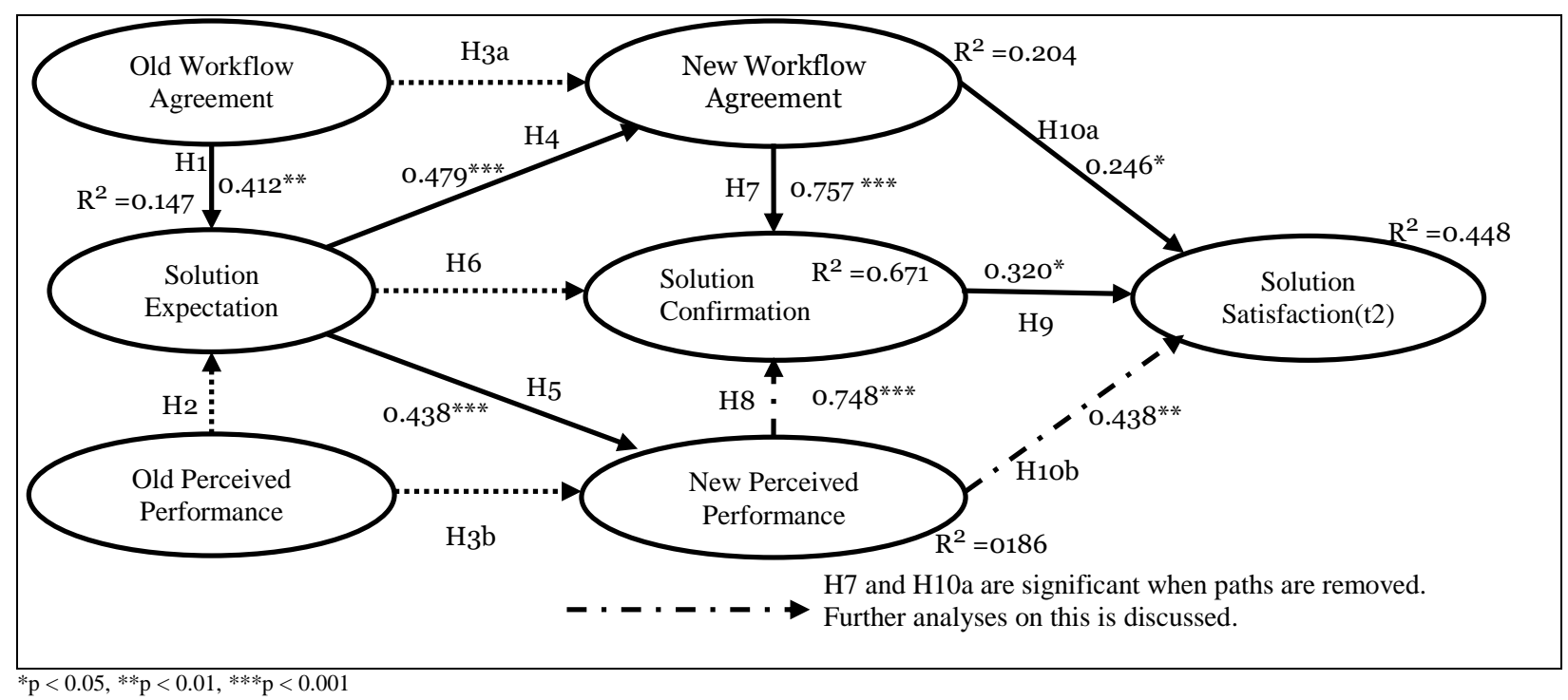

\section{Discussion}

Figure 1. Research Model and Estimates

For brevity, all key findings are presented in figure 1. The comparative model, tested, had two mediated routes between user expectation and solution satisfaction: One route is through workflow agreement and the other through perceived performance. The model was tested with longitudinal survey observations collected from 118 participants in an organization that recently underwent a major transition in electronic workflow. In the overall (comparative) model testing, the paths in perceived performance route were significant, but those in the workflow agreement route were not significant. When the perceived performance route was suppressed, however, the workflow agreement route became significant. Each of the routes, when tested separately, predicted the same adjusted R-squared adjusted value in solution satisfaction. The preliminary results underscore the relative importance of user workflow agreement compared with user's perceived performance measures on the system. In the post hoc analyses, all the insignificant paths in the default model were consistently not significant except the paths for $\mathrm{H} 7$ and H10a which were significant when our comparison construct, new perceived performance was not included in the model.

\begin{tabular}{|l|l|c|c|c|c|c|c|c|c|c|c|}
\hline \multicolumn{1}{|c|}{ Variable } & Mean & SD & $\mathbf{C R}$ & $\mathbf{1}$ & $\mathbf{2}$ & $\mathbf{3}$ & $\mathbf{4}$ & $\mathbf{5}$ & $\mathbf{6}$ & $\mathbf{7}$ & $\mathbf{8}$ \\
\hline 1. New Perc. Performance & 5.36 & 1.15 & .95 & $\mathbf{. 9 1}$ ^^ & & & & & & & \\
\hline 2. New Workflow Agreement & 5.31 & 1.22 & .93 & $.91^{\wedge}$ & $\mathbf{. 8 7}$ & & & & & & \\
\hline 3.Old Perceived Performance & 4.23 & 1.40 & .90 & .08 & .08 & $\mathbf{. 8 4}$ & & & & & \\
\hline 4.Old Workflow Agreement & 4.29 & 1.18 & .84 & .11 & .09 & .70 & $\mathbf{. 7 5}$ & & & & \\
\hline 5.Solution Confirmation & 5.25 & 1.19 & .93 & .82 & .76 & .11 & .14 & $\mathbf{. 9 1 *}$ & & & \\
\hline 6.Solution Expectation & 5.17 & 1.20 & .92 & .43 & .44 & .24 & .38 & .33 & $\mathbf{. 8 9} *$ & & \\
\hline 7.Solution Satisfaction(t2) & 5.14 & 1.18 & .96 & .64 & .58 & .03 & .08 & .63 & .21 & $\mathbf{. 9 2 *}$ & \\
\hline 8.Old Solution Satisfaction (t1) & 5.02 & 1.11 & .93 & -.09 & -.88 & .19 & .04 & -.02 & -.07 & .11 & $\mathbf{. 8 8}$ \\
\hline
\end{tabular}

*Square root of the AVE's shown as outer diagonal values. ${ }^{\wedge}$ Not discriminately valid. Perceived Performance included for comparison purposes but would not be included in a final theory that explains the impact of changes in workflow agreement on solution satisfaction in a mandatory setting.

Table 1. Discriminant validity, correlations, and composite reliability

Importantly, the adjusted R-squared values and other estimations remained, approximately, the same. This underscores the relative importance of user workflow agreement as compared to perceived performance measures on the system. This finding is consistent with prior literature which suggests that effective tasks appropriation is positively related to perceived performance as already established in the extant 
literature (e.g., Goodhue and Thompson [14]). How this relationship plays out has been shown in this study. Our findings also show users form expectations about technology solutions regarding new workflows and new performance after system changes based on old workflow experiences. This phenomenon explains the significance in $\mathrm{H} 1$ and the insignificance in $\mathrm{H} 2$. However, in the post hoc analysis, we find that old perceived performance predicts an initial affective measure of satisfaction (old solution satisfaction at $\mathrm{t} 1$ regarding old technology features). However, this initial satisfaction is not significantly related to any other construct except new solution satisfaction (t2). This finding may not be surprising. Prior studies have established the inconsistency in the findings that performance expectations are linked to old experiences. The inconsistencies have been attributed to the context and the product (IT artifact in our case) under consideration [18]. Again, although the relationship between solution expectation and solution confirmation was not significant (H6) contrary to our hypothesis, the finding may be valid. We reason that expectations are formed based on some objectified outcome when the user has some knowledge or perception about this objectified outcome. With this, a confirmation or disconfirmation ensues implying that the objectified outcome plays a full mediating role. Further studies may test this assumption. The above explanation underlies the phenomena in $\mathrm{H} 4$ and $\mathrm{H} 5$ where both hypotheses when H6 was not supported.

The present study contributes to the IS literature in several ways. First, we add to the conceptions of deep structure usage of a technology system [34]. This is attained by measuring unique workflows (tasks), specific user involvement (user) and a specific appropriation of this workflow about a technology feature (system). The context of study - mandatory settings - also enriches the contribution to deep structure conceptualization. In a mandatory setting, a user has a responsibility to use the system, however, how well the system is used (the extent of faithful appropriation) regarding changes in workflows in the organization and its impact has been shown in this study. Relatedly, we measured the change in satisfaction of the users regarding the solutions that these workflows enabled in their use of the new technology feature. This contributes to the literature and theoretical foundations of IS continuance studies (e.g., Bhattacherjee [5]) and consumer repurchase intentions (via job performance in the marketing literature). Although our study did not focus on intention to continue, the IS and marketing literature suggest that satisfaction is a key predictor of intention to continue and consequently continual use (or repurchase). Thus, an increase in individuals' satisfaction would positively affect continual engagement with the technology or artifact. However, we argue that in a mandatory setting, positing that users would continue usage is necessary but not sufficient for the overall optimization of an organization' productivity [24]. In our post hoc analysis, we evaluated the change in satisfaction based on old experiences and the new experiences. We refer to this as a notion of rate of continuance. We hope to interrogate this phenomenon further to ground its contribution to the IS continuance literature. Also, our study contributes to the adoption literature, and cognitive motivations of IT use which highlight late adoption or post-adoptive behaviors (e.g., Jasperson and others [17]). This literature mainly explains adoption mechanisms of users based on other users' earlier appropriations of a technology. Our study deals with the cognitive processes of the same users, pre- and post-, in explicating their experiences in mandatory settings and how temporal differences in cognitive agreement about their workflows could be understood. Finally, by integrating workflow agreement and perceived performance with the expectation-confirmation theory, this study provides a unique response to the call for combining cognitive and affective processes to enrich IT use theorizations $[4,27]$

\section{Limitations, Future Directions, and Implication of Study}

Although this study attempted to empirically investigate and provide insight into the effect of implementing changes to workflows, the study could be more rigorous if more than one workflow on both systems (old and new) is measured. Several workflows may show different results. For instance, a group of workflows may be performed by a user and the measurement of workflow agreement regarding the complex relationships of these workflows can be an interesting study.

As research respondents continue to use the technology system (campus solution B), an opportunity is provided to collect more longitudinal data to assess the predictive strength of the model and the estimates. Again, this would afford future studies to explore the notion of rate of continuance as users' changing preferences modify new workflow agreement. This notion was not the focus of the study; hence it provides an avenue for further studies to be carried out at different levels of analysis. Additionally, statistical tests for checking any potential common method bias in data collection would carried out. In relation, a confirmatory factor analysis with covariance-based SEM would be employed for data analysis to assess the 
robustness of the research model. Finally, we did not control for ease of use and training, because the assumption was that the students were technologysavvy and had been using the technology system for some time. This is supported by the insignificance in the test for the effect of usage length (as a control variable) on the results. However, these would be tested subsequently, to provide statistical proof.

The study provides several implications for practice as far as introducing new technologies are concerned and ensuring their continual use. By highlighting the role of users' cognitive agreement with their new workflows as almost synonymous to how new performances are perceived, managers could ensure continual usage by employing focal discussions amongst users to develop generally acceptable workflows regarding their most salient tasks in the organization. Such actions will serve to increase users' satisfaction with the system.

\section{Conclusion}

The study focused on users' aggregate cognitions on new workflows and how these relate to users' satisfaction about the solution the workflow management system offers. Empirical analysis was based on data collected over two time-periods; before and after technology-induced workflow changes. The findings show that experiences and cognitive agreements about new workflows are relevant, just as much as users' the task performances that are enabled by a system.

\section{References}

[1] Agarwal, R., and E. Karahanna, "Time Flies When You're Having Fun: Cognitive Absorption and Beliefs about Information Technology Usage", MIS Quarterly 24(4), 2000, pp. 665 .

[2] Barki, H., R. Titah, and C. Boffo, "Information System Use-Related Activity: An Expanded Behavioral Conceptualization of Individual-level Information System Use," Information Systems Research 18(2), 2007, pp. 173192.

[3] Barlow, J.B., M. Warkentin, D. Ormond, and A.R. Dennis, "Don't Even Think About It! The Effects of Antineutralization, Informational, and Normative Communication on Information Security Compliance", Journal of the Association for Information Systems 19, 2018, pp. 689-715.

[4] Beaudry, A., and A. Pinsonneault, "The Other Side of Acceptance: Studying the Direct and Indirect Effects of
Emotions on Information Technology Use", MIS Quarterly 34(4), 2010, pp. 689-710.

[5] Bhattacherjee, A., "Understanding Information Systems Continuance: An Expectation-Confirmation Model", MIS Quarterly 25(3), 2001, pp. 351.

[6] Bhattacherjee, A., and C.P. Lin, "A Unified Model of IT Continuance: Three Complementary Perspectives and Crossover Effects.", European Journal of Information Systems 24(4), 2015, pp. 364-373.

[7] Bhattacherjee, A., J. Perlos, and C. Sanford, "Information Technology Continuance: A Theoretical Extension and Empirical Test", The Journal of Computer Information Systems 49(1), 2008, pp. 17-26.

[8] Bhattacherjee, A., and G. Premkumar, "Understanding Changes in Belief and Attitude Toward Information Technology Usage: A Theoretical Model and Longitudinal Test," MIS Quarterly 28(2), 2004.

[9] Burton-Jones, A., and D.W. Straub, "Reconceptualizing System Usage: An Approach and Empirical Test", Information Systems Research 17(3), 2006, pp. 228-246.

[10] Burton-Jones, A., and O. Volkoff, "How Can We Develop Contextualized Theories of Effective Use? A Demonstration in the Context of Community-Care Electronic Health Records", Information Systems Research Articles $i$, 2017, pp. 1-22.

[11] Chin, W.W., A. Gopal, and W.D. Salisbury, "Advancing the Theory of Adaptive Structuration: The Development of a Scale to Measure Faithfulness of Appropriation", Information Systems Research 8(4), 1997, pp. 342-367.

[12] Dabholkar, P.A., C.D. Shephered, and D.I. Thorpe, “A Comprehensive Framework for Service Quality: An Investigation of Critical Conceptual and Measurement Issues Through a Longitudinal Study", Journal of Retailing 76(2), 2000, pp. 139-173.

[13] Festinger, L., and J.M. Carlsmith, "Cognitive Consequences of Forced Compliance", Journal of Abnormal and Social Psychology 58, 1959, pp. 203-210.

[14] Goodhue, D.L., and R.L. Thomspon, "Task-Technology Fit and Individual Performance", MIS Quarterly 19(2), 1995, pp. 213-236.

[15] Hossain, M.A., and M. Quaddus, "ExpectationConfirmation Theory in Information System Research: A Review and Analysis", In Information Systems Theory: Explaining and Predicting Our DIgital Society. Springer Science and Business Media, New York, NY, 2012, 441469. 
[16] Islam, A.K.M.N., M. Mäntymäki, and A. Bhattacherjee, "Towards a Decomposed Expectation-Confirmation Model of IT Continuance: The Role of Usability", Communications of the Association for Information Systems 40, 2017, pp. 502-523.

[17] Jasperson, J. (Sean), P.E. Carter, and R.W. Zmud, “A Comprehensive Conceptualization of Post-Adoptive Behaviours Associated with Information Technology Enabled Work Systems.", MIS Quarterly 29(3), 2005, pp. 525-557.

[18] Johnson, M.D., G. Nader, and C. Fornell, "Expectations, Perceived Performance, and Customer Satisfaction for a Complex Service: The Case of Bank Loans", Journal of Economic Psychology 17(2), 1996, pp. 163-182.

[19] Kjaergaard, A.L., and T.B. Jenson, "Using Cognitive Mapping to Represent and Share Users' Interpretations of Technology", Communications of the Association for Information Systems 34(57), 2014, pp. 1097-1114.

[20] Morris, M.G., and V. Venkatesh, "Understanding the Role of Enterprise Resource Planning System Implementation", Source: MIS Quarterly 34(1), 2010, pp. 143-161.

[21] Oliver, R.L., "A Cognitive Model of the Antecedents and Consequences of Satisfaction Decisions", Journal of Marketing Research 17(4), 1980, pp. 460.

[22] Orlikowski, W.J., and C.S. Iacono, "Desperately Seeking the 'IT'in IT Research: A Call to Theorizing the IT Artifact", Information Systems Research 12(2), 2001, pp. $121-134$.

[23] Raia, M., "The Cost of Doing Nothing About Your Workflow Issues", www.integrify.com, 2016. https://www.integrify.com/blog/posts/cost-nothingworkflow-issues/

[24] Sasidharan, S., R. Santhanam, D.J. Brass, and V. Sambamurthy, "The Effects Of Social Network Structure on Entreprise Systems Success: A Longitudinal Multilevel Analysis", Information System Research 23(3), 2012, pp. 658-678.

[25] Sharma, R., and P. Yetton, "The Contingent Effects of Management Support and Task Interdependence on
Successful Information Systems Implementation", MIS Quarterly 27(4), 2003, pp. 533-556.

[26] Sharma, R., and P. Yetton, "The Contingent Effects of Training, Technical Complexity, and Task Interdependence on Successful Information Systems Implementation", Mis Quarterly 31(2), 2007, pp. 219-238.

[27] Stein, M.-K., S. Newell, E.L. Wagner, and R.D. Galliers, "Coping With Information Technology: Mixed Emotions, Vacillation, and Nonconforming Use Patterns", MIS Quarterly 39(2), 2015, pp. 367-392.

[28] Sun, Y., Y. Fang, K.H. Lim, and D. Straub, "User Satisfaction with Information Technology Service Delivery: A Social Capital Perspective", Information Systems Research 23(4), 2012, pp. 1195-1211.

[29] Sykes, T.A., and V. Venkatesh, "Explaining PostImplementation Employee System and Source of Social Network Ties", Management Information Systems Quarterly 41(3), 2017, pp. 917-936.

[30] Sykes, T.A., V. Venkatesh, and J.L. Johnson, "Enterprise System Implementation and Employee Job Performance: Understanding the Role of Advice Networks", MIS Quarterly 38(1), 2014, pp. 51-72.

[31] Wei, C.-P., P.J.-H. Hu, and Y.-H. Lee, "Preserving User Preferences in Automated Document-Category Management: An Evolution-Based Approach", Journal of Management Information Systems 25(4), 2009, pp. 109-144.

[32] Xu, J. (David), S. Abdinnour, and B. Chaparro, "An Integrated Temporal Model of Belief and Attitude Change: An Empirical Test With the iPad.", Journal of the Association for Information Systems 18(2), 2017, pp. 113140 .

[33] Zammuto, R.F., T.L. Griffith, A. Majchrzak, D.J. Dougherty, and S. Faraj, "Information Technology and the Changing Fabric of Organization", Organization Science 18(5), 2007, pp. 749-762.

[34] Zhang, X., "Knowledge Management System Use and Job Performance: A Multilevel Contingency Model", MIS Quarterly 41(3), 2017, pp. 811-840. 